\title{
Evaluation of the vector competence of a native UK mosquito Ochlerotatus detritus (Aedes detritus) for dengue, chikungunya and West Nile viruses
}

\author{
Marcus S. C. Blagrove ${ }^{1,2^{*}}$, Ken Sherlock', Gail E. Chapman ${ }^{1}$, Daniel E. Impoinvil ${ }^{3}$, Philip J. McCall ${ }^{4}$, \\ Jolyon M. Medlock ${ }^{2,5}$, Gareth Lycett ${ }^{4}$, Tom Solomon ${ }^{1,2}$ and Matthew Baylis ${ }^{1,2}$
}

\begin{abstract}
Background: To date there has been no evidence of mosquito-borne virus transmission of public health concern in the UK, despite the occurrence of more than 30 species of mosquito, including putative vectors of arboviruses. The saltmarsh mosquito Ochlerotatus detritus [syn. Aedes (Ochlerotatus) detritus] is locally common in parts of the UK where it can be a voracious feeder on people.

Methods: Here, we assess the competence of $O$. detritus for three major arboviruses: dengue virus (DENV), chikungunya virus (CHIKV) and West Nile virus (WNV) using adult mosquitoes reared from wild, field-obtained immatures.

Results: We demonstrate laboratory competence for WNV at $21{ }^{\circ} \mathrm{C}$, with viral RNA detected in the mosquito's saliva 17 days after oral inoculation. By contrast, there was no evidence of laboratory competence of $O$. detritus for either DENV or CHIKV.

Conclusions: To our knowledge, this is the first study to demonstrate competence of a UK mosquito for WNV and confirms that $O$. detritus may present a potential risk for arbovirus transmission in the UK and that further investigation of its vector role in the wild is required.
\end{abstract}

Keywords: DENV, WNV, CHIKV, Arbovirus, Aedes, Ochlerotatus, Mosquito, Vector competence

\section{Background}

Although there have been 34 species of mosquito reported in the British Isles [1], including 12 known competent vectors of arboviruses elsewhere [2], no confirmed incidences of mosquito-borne virus transmission to humans has been recorded in the British Isles [3].

Ochlerotatus detritus [syn. Aedes (Ochlerotatus) detritus] is abundant throughout coastal regions of the British Isles, with immature mosquitoes commonly found in coastal brackish waters, particularly those prone to flooding at both the spring high tide zone and in regularly flooded saline lagoons $[4,5]$. Ochlerotatus detritus is a multivoltine species,

\footnotetext{
* Correspondence: marcus.blagrove@liverpool.ac.uk

${ }^{1}$ Department of Epidemiology and Population Health, Institute of Infection and Global Health, University of Liverpool, Liverpool, UK

${ }^{2}$ National Institute of Health Research Health Protection Research Unit in Emerging and Zoonotic Infections, University of Liverpool, Liverpool, UK

Full list of author information is available at the end of the article
}

producing large populations following each spring flood of areas where eggs have previously been deposited awaiting saline submergence. Eggs of $O$. detritus can survive for over a year [6], with peak adult activity occurring between March and November when, in coastal areas, they are often the greatest biting nuisance of any British mosquito [7]. Although it is primarily a coastal species, there is evidence of populations inland in freshwater habitats [8]. Ochlerotatus detritus has a highly catholic feeding behaviour, commonly feeding on humans, birds and livestock [7], thus also making it a potential bridge vector of many zoonotic arboviruses. It has been implicated as the most common nuisance biting species of humans in England [9] and the most common mosquito of newly created coastal habitat [5].

With increasing global travel of both humans and livestock, as well as changing global climatic conditions, the geographic range of many mosquito-borne arboviruses 
has been increasing in recent decades. The most prominent examples of this phenomenon are West Nile virus (WNV), dengue virus (DENV) and chikungunya virus (CHIKV).

WNV has expanded its range from a small area of sub-Saharan Africa to the six major continents in the last 25 years [10]. Outbreaks of WNV in Europe occur annually and given that the virus can be moved around the continent in migratory birds, there would appear to be a route of entry for the virus in the United Kingdom (UK). Furthermore, WNV occurs in regions in similar climatic conditions to the UK such as Canada [11]. Moreover, antibodies have been detected in migratory and domestic birds in the UK $[12,13]$ indicating that the UK may be at risk of the establishment of WNV.

The incidence of new dengue cases globally is estimated to have increased 30 -fold in the last 50 years $[14,15]$. This can in part be attributed to an increase in the geographical range of the virus and an increase in the human population within, and travelling to, high risk areas [16]. The geographical range of CHIKV has also increased over a similar time period, with more recent expansions believed to be the result of a range of novel mutations increasing the replication rate in Ae. albopictus [17]. Furthermore, there has also been a significant expansion of CHIKV to the Americas with a large outbreak ( $>1$ million cases) in the Caribbean region. The occurrence of these viruses circulating in geographical regions where there are increased numbers of UK travellers poses a potential risk for the virus to spread to the UK through infected travellers [3]. The range expansion of both of these viruses has included an extension into regions with cooler climates, including sporadic autochthonous transmission as far north as France, highlighting the potential future risk to the UK $[18,19]$.

Previously, our group has demonstrated that fieldcollected $O$. detritus are competent laboratory vectors of Japanese encephalitis virus (JEV), showing potential for transmission by the mosquito at 7 days post-infection at $23{ }^{\circ} \mathrm{C}[20]$. Given this, as well as the high abundance and biting nuisance of $O$. detritus, it is important to determine whether $O$. detritus is a laboratory-competent vector of the aforementioned invasive arboviruses in order to determine the risk to the UK from this potential vector. In this study, we attempted to infect $O$. detritus experimentally with three of the most globally important and invasive arboviruses, WNV, DENV and CHIKV, in order to determine the vector competence of this species.

\section{Methods}

Ochlerotatus detritus immatures (fourth-instar larvae and pupae) were collected from marshland by Little Neston, Cheshire, UK (GPS coordinates: $53^{\circ} 16^{\prime} 37.2^{\prime \prime} \mathrm{N}$, $\left.3^{\circ} 04^{\prime} 06.4^{\prime \prime} \mathrm{W}\right)$. Immatures were collected using a fine scrim net and non-mosquitoes were removed from the sample using a Pasteur pipette. Immatures were reared in ambient conditions in water collected from their larval habitat until adulthood; no additional food source was provided in order to ensure the mosquitoes remained as representative of the wild population as possible. Adults were allowed to emerge and mate in $30 \times 30 \times 30 \mathrm{~cm}$ BugDorms (BugDorm, Taichung, Taiwan). Control colony Ae. aegypti (New Orleans strain) (DENV and CHIKV) and $C x$. quinquefasciatus (Recife strain) (WNV) were used for comparison. Colony mosquitoes were reared in an insectary at $25{ }^{\circ} \mathrm{C} 12: 12$ light:dark photoperiod and $70 \%$ relative humidity $(\mathrm{RH})$.

At seven days post-emergence, female adults were removed and transferred into $1 \mathrm{l}$ cylindrical polypropylene DISPO-SAFE containers, with a fine mesh covering the container opening and stored for $24 \mathrm{~h}$ with no access to sugar. Blood meals (heparinised human blood, NHS transfusion service, Speke) containing virus (or blood only control) were provided for $3 \mathrm{~h}$ with an odorised feeding membrane. Unfed adults were removed from the cage, and the fed mosquitoes were incubated at $21{ }^{\circ} \mathrm{C}$ and $70 \%$ RH for 17 days. Mortality was recorded $48 \mathrm{~h}$ and 17 days after feeding. $21{ }^{\circ} \mathrm{C}$ was used as this approximates a very hot summer in the south east of England. 17 days (as opposed to the standard 14 days) was used to counter the likely lengthy increase in extrinsic incubation period as a result of the relatively low experimental temperatures.

The virus strains were as follows: WNV NY-99, cultured at Public Health England, Porton Down, Surrey, in Vero cells; DENV Serotype 2, Bangkok Thailand; CHIKV NC/ 2011-568 (CHIKV_NC) cultured by the Brain Infections Group, University of Liverpool, in Vero cells. Final titres of virus in blood were as follows: WNV $2 \times 10^{6} \mathrm{PFU} / \mathrm{ml}$; CHIKV $1 \times 10^{7} \mathrm{PFU} / \mathrm{ml}$; DENV $1 \times 10^{7} \mathrm{PFU} / \mathrm{ml}$, titres were limited by the available stock concentration provided by the respective institutions. Virus strains were confirmed by sequencing prior to experimentation.

On day 17, mosquitoes were anaesthetised with FlyNap (Carolina Biological Supply Company, Burlington, North Carolina, USA), and their saliva was extracted by inserting their proboscis into a capillary tube containing mineral oil. RNA was extracted from the expectorate using TRIzol reagent (Thermo Fisher Scientific). cDNA was generated using Superscript Vilo (Thermo Fisher Scientific).

An additional experiment was performed for DENV using different conditions in an attempt to establish the cause of mortality in $O$. detritus fed with this virus. A $1 / 100$ concentration condition was produced by serial dilution with blood, and a deactivated virus condition was produced by heating the virus (prior to adding to blood) to $70{ }^{\circ} \mathrm{C}$ for $10 \mathrm{~min}$ in a water bath.

Taqman (Thermo Fisher Scientific) quantitate reverse transcription polymerase chain reaction (qRT-PCR) was 
used to detect the presence of viral RNA in the samples. Primer and probe sets were as follows: WNV, sense $5^{\prime}$ CCA CCG GAA GTT GAG TAG ACG-3', anti-sense 5'-TTT GGT CAC CCA GTC CTC CT-3', probe Cy5TGC TGC CTG CGG CTC AAC CC-BBQ, regimen 1 min at $95^{\circ} \mathrm{C}$ followed by 40 cycles of $95^{\circ} \mathrm{C}$ for $5 \mathrm{~s}$ and $60{ }^{\circ} \mathrm{C}$ for $8 \mathrm{~s}$ [21]. CHIKV, sense 5'-GCA TCA GCT AAG CTC CGG GTC-3', anti-sense 5' -CAA TGT CTT CAG CCT GGA CAC C-3', probe Cy5-ATG CAA ACG GCG ACC ATG CCG TCA-BBQ, regimen $95{ }^{\circ} \mathrm{C}$ for 2 min followed by 40 cycles of $95{ }^{\circ} \mathrm{C}$ for $15 \mathrm{~s}, 55^{\circ} \mathrm{C}$ for $10 \mathrm{~s}, 6{ }^{\circ} \mathrm{C}$ for $10 \mathrm{~s}$ and $72{ }^{\circ} \mathrm{C}$ for $20 \mathrm{~s}$ [22]. DENV, sense 5'-GAC TAG YGG TTA GAG GAG ACC-3', anti-sense 5'-GHR GAG ACA GCA GGA TCT CTG-3', probe JOE-AAG GAC TAG MGG TTA GWG GAG ACC C-BBQ, regimen $95{ }^{\circ} \mathrm{C}$ for $2 \mathrm{~min}$ followed by 40 cycles of $95{ }^{\circ} \mathrm{C}$ for $15 \mathrm{~s}, 55^{\circ} \mathrm{C}$ for $10 \mathrm{~s}, 60{ }^{\circ} \mathrm{C}$ for $10 \mathrm{~s}$ and $72{ }^{\circ} \mathrm{C}$ for $20 \mathrm{~s}$ [22]. Positive controls (neat virus) and negative control (neat blood) were performed alongside all qRT-PCR experiments.

\section{Results}

No virus-positive expectorate was recorded for $O$. detritus with CHIKV, although $61 \%$ of Ae. aegypti were found to be virus-positive (Table 1). No significant difference was found between the mortality rate of $O$. detritus and Ae. aegypti infected with CHIKV at $48 \mathrm{~h}$ (Fisher's exact test, two-tailed, $P=0.529)$. However, the mortality rate of $O$. detritus was significantly higher at 17 days (Fisher's exact test, two-tailed, $P=0.001$ ). Blood only controls from the DENV experiment below were qRT-PCR tested for CHIKV as a negative control; all individuals tested negative.

In the first replicate of the DENV experiment, within 48 h, $98 \%$ of all blood-fed female O. detritus had died (whilst almost no unfed-females died), compared to $3 \%$ mortality in Ae. aegypti (Fisher's exact test, two-tailed, $P<0.0001)$. The experiment was repeated using four conditions: full concentration DENV (replicate 2); 1/100 dilution of virus; a heat deactivated full concentration virus; and blood only (Table 2). $48 \mathrm{~h}$ mortality was again very high (>90\%) with full concentration DENV (replicate 2), and again significantly higher than that of Ae. aegypti (Fisher's exact test, two-tailed, $P<0.0001$ ); no significant difference was found between the two full concentration replicates (Fisher's exact test, two-tailed, $P=0.4863$ ). The
$48 \mathrm{~h}$ mortality rate was significantly reduced by the virus being diluted to $1 / 100$ concentration (Fisher's exact test, two-tailed, $P<0.0001$ ), as well as by the virus being heatdeactivated (Fisher's exact test, two-tailed, $P<0.0001$ ). There was no significant difference between $48 \mathrm{~h}$ mortalities with deactivated or diluted virus (Fisher's exact test, two-tailed, $P=0.580$ ); however, both deactivated and diluted virus cause significantly higher mortality at $48 \mathrm{~h} \mathrm{com-}$ pared to the no virus (blood only) control (Fisher's exact test, two-tailed, $P=0.0006$ and $P<0.0001$, respectively).

Twenty-one \% of the surviving $O$. detritus blood-fed females at 17 days were virus-positive for WNV, compared to $53 \%$ Cx. quinquefasciatus (Table 3) (Fisher's exact test, two-tailed, $P<0.0001)$. The mortality rate of $C x$. quinquefasciatus was significantly higher than that of $O$. detritus, when infected with WNV, at both $48 \mathrm{~h}$ (Fisher's exact test, two-tailed, $P<0.0001$ ), and 17 days (Fisher's exact test, two-tailed, $P<0.0001$ ). Blood only controls from the DENV experiment below were qRTPCR tested for WNV as a negative control; all individuals tested negative.

The relative quantities of virus for each experiment are shown in Fig. 1 (multiple entries for O. detritus and DENV were not made as all equalled zero). There was no significant difference between the relative quantity of WNV virus recovered from the expectorate of $O$. detritus and $C x$. quinquefasciatus (Wilcoxon rank sum test, two tailed, $P=0.1674$ ).

\section{Discussion}

In this study the abundant, but locally restricted, British mosquito $O$. detritus was assessed for its competence for DENV, CHIKV and WNV; O. detritus was shown to be competent for only WNV. To our knowledge, this is the first demonstration that a wild-caught British mosquito is laboratory-competent for WNV and the first demonstration that $O$. detritus is laboratory-competent for WNV.

Our results raise the question as to whether $O$. detritus may be an efficient vector for WNV in the wild with the potential to sustain local transmission of WNV in the event of introduction of the virus to the UK. Furthermore, there was no significant difference between the amount of virus recovered from the expectorate of $O$. detritus and the known vector $C x$. quinquefasciatus. Given both the catholic feeding habits of $O$. detritus

Table 1 Mortality and competence of Ochlerotatus detritus for CHIKV

\begin{tabular}{|c|c|c|c|c|c|c|}
\hline Species & $\begin{array}{l}\text { No. of mosquitoes } \\
\text { fed }\end{array}$ & $\begin{array}{l}\text { Mosquito mortality } \\
\text { at } 48 \mathrm{~h}(\%)\end{array}$ & $\begin{array}{l}\text { Mosquito mortality } \\
\text { at } 17 \text { day (\%) }\end{array}$ & $\begin{array}{l}\text { No. of fed mosquitoes } \\
\text { positive (\%) }\end{array}$ & $\begin{array}{l}\text { Percentage of mosquitoes } \\
\text { positive }^{\mathrm{a}}\end{array}$ & $\begin{array}{l}\text { Percentage of surviving } \\
\text { mosquitoes positive }\end{array}$ \\
\hline O. detritus & 143 & $13(9.1)$ & $41(28.7)$ & 0 & 0 & 0 \\
\hline Ae aegypti & 158 & $11(7.0)$ & 21 (13.3) & 83 & 52.5 & 60.6 \\
\hline
\end{tabular}

${ }^{a}$ Number of positive/Total number of mosquitoes at 17 days

${ }^{\mathrm{b}}$ Number of positive/Number of mosquitoes alive at 17 days 
Table 2 Mortality and competence of Ochlerotatus detritus for DENV

\begin{tabular}{llllllll}
\hline Species & Condition & $\begin{array}{l}\text { No.quitoes } \\
\text { fed }\end{array}$ & $\begin{array}{l}\text { Mosquito mortality } \\
\text { at 48 h (\%) }\end{array}$ & $\begin{array}{l}\text { Mosquito } \\
\text { mortality at } \\
17 \text { day (\%) }\end{array}$ & $\begin{array}{l}\text { No. of fed } \\
\text { mosquitoes } \\
\text { positive }\end{array}$ & $\begin{array}{l}\text { Percentage of } \\
\text { mosquitoes } \\
\text { positive }^{a}\end{array}$ & $\begin{array}{l}\text { Percentage of surviving } \\
\text { mosquitoes positive }\end{array}$ \\
\hline O. detritus & Full rep 1 & 982 & $959(97.7)$ & $982(100)$ & 0 & 0 & 0 \\
& Full rep 2 & 93 & $90(96.8)$ & $93(100)$ & 0 & 0 & 0 \\
& 1/100 & 102 & $21(20.6)$ & $34(33.3)$ & 0 & 0 & 0 \\
& Deactivated & 89 & $15(16.9)$ & $28(31.5)$ & 0 & 0 & 0 \\
& Blood only & 94 & $2(2.1)$ & $17(18.1)$ & 0 & 0 & 0 \\
Ae. aegypti & Full & 207 & $6(2.9)$ & $25(12.1)$ & 127 & 61.4 & 69.8
\end{tabular}

${ }^{a}$ Number of positive/Total number of mosquitoes at 17 days

${ }^{b}$ Number of positive/Number of mosquitoes alive at 17 days

(feeding on birds, livestock and humans) and the evidence presented here of its laboratory competence for WNV transmission, we suggest that the role of $O$. detritus as a potential risk for WNV reservoir circulation in birds, transmission to humans and transmission to horses requires consideration. WNV is considered to have been introduced into North America by either migratory birds or exotic birds transported via aeroplane [23]. Such a method of introduction is possible in the UK [24], indeed, there has been evidence of WNV antibodies in migratory and domestic birds in the UK, suggesting that invasion is possible [12,13]. Given this and the expansion of the range of WNV to areas with similar climates to the UK, it would appear that the UK may be at risk of WNV introduction and circulation. Important next steps in the analysis of risk from this vector/virus combination are an assessment of the effects of temperature and viral titre on competence in order to determine the likelihood of virus transmission and whether UK temperatures would be sufficient to sustain it.

In contrast to the competence of $O$. detritus for WNV, our data show that the mortality of $O$. detritus may be greatly increased by oral infection with DENV. We found a highly significant increase in the mortality of $O$. detritus compared to Ae. aegypti when using full concentration virus. However, we also showed that 'deactivating' the virus did not completely negate the increased mortality, and that there was no significant difference between low titre and deactivated virus. These findings could also be consistent with a contaminant causing mortality (however, no unusual mortality was observed with Ae. aegypti). This effect of DENV on O. detritus warrants further study; whilst it does not prove that DENV is causing the mortality, it is consistent with this theory and similar effects have been noted in some previous studies. Whilst most studies have shown no fitness costs of DENV to its host, e.g. [25], there are some previously described incidences of arboviruses causing fitness costs to their vectors, including reduced longevity of Ae. aegypti infected with DENV [26-28]. Reduced longevity has also been observed with other arboviruses such as Western equine encephalitis virus (WEEV) and Eastern equine encephalitis virus (EEEV) $[29,30]$. These studies however, show a relatively minor effect on longevity compared to the data presented here. This is likely the result of previous studies focusing on the fitness effects of arboviruses on their natural vectors; given the geographical ranges of DENV and $O$. detritus, it is extremely unlikely that DENV has adapted to minimize any negative fitness effects on $O$. detritus. Our data are therefore consistent with the prevailing theory that arboviruses adapt to minimize their effect on the longevity of their natural vectors and may have significantly greater fitness effects on non-natural vectors [31].

Given both the extreme effect on longevity, together with the lack of any virus in the expectorate of $O$. detritus in the low-dose DENV condition, it seems highly unlikely that $O$. detritus will pose a significant future risk of DENV transmission in the UK.

Table 3 Mortality and competence of Ochlerotatus detritus for WNV

\begin{tabular}{llllllc}
\hline Species & $\begin{array}{l}\text { No. of } \\
\text { mosquitoes } \\
\text { fed }\end{array}$ & $\begin{array}{l}\text { Mosquito } \\
\text { mortality at } \\
48 \mathrm{~h} \mathrm{( \% )}\end{array}$ & $\begin{array}{l}\text { Mosquito } \\
\text { mortality at } \\
17 \text { day (\%) }\end{array}$ & $\begin{array}{l}\text { No. of fed } \\
\text { mosquitoes } \\
\text { positive (\%) }\end{array}$ & $\begin{array}{l}\text { Percentage of } \\
\text { mosquitoes } \\
\text { positive }^{\text {a }}\end{array}$ & $\begin{array}{l}\text { Percentage of surviving } \\
\text { mosquitoes positive }\end{array}$ \\
\hline O. detritus & 89 & $2(2.2)$ & $11(12.4)$ & 16 & 17.9 & 20.5 \\
CX. quinquefasciatus & 143 & $26(18.2)$ & $53(37.1)$ & 48 & 33.6 & 53.3 \\
\hline
\end{tabular}

aNumber of positive/Total number of mosquitoes at 17 days

${ }^{b}$ Number of positive/Number of mosquitoes alive at 17 days 




Fig. 1 Relative quantity of viral RNA in expectorate determined by qRT-PCR. All virus-positive results are shown as a quantity relative to the mean titre of the control vector (Ae. aegypti for CHIKV and DENV; and Cx. quinquefasciatus for WNV). Horizontal bars represent the mean

Our results also show no evidence for vector competence of O. detritus for CHIKV. Unlike the DENV infection however, CHIKV caused no significant mortality. The colony Ae. aegypti control infection did produce infectious females at 17 days at $21^{\circ} \mathrm{C}$, ruling out inactive virus. Whilst it is not known whether higher temperatures or increased time to expectorate extraction would produce infectious $O$. detritus, the failure to detect any CHIKV despite the long incubation period provides no evidence for risk of CHIKV transmission from this population of $O$. detritus.

\section{Conclusions}

In addition to our previous work showing competence of $O$. detritus for JEV [20], here, we have shown that there appears to be no evidence to suggest that there is a risk to the UK from O. detritus vectoring either DENV or CHIKV, but in contrast there is a potential risk in its role as a putative WNV vector. Ochlerotatus detritus is a nuisance mosquito species in the UK, and can be highly abundant in some coastal habitats. Given both the competence and feeding habits of $O$. detritus, this species may pose a credible threat for transmission of both JEV and WNV. To our knowledge, this is the first time wild UK mosquitoes have been demonstrated to be laboratory competent for WNV. However, further work is required to understand whether this laboratory competence translates into a risk of transmission in natural environments.

\section{Abbreviations}

Not applicable.

Acknowledgements

Not applicable.

\section{Funding}

This work was funded by a Biotechnology and Biological Sciences Research Council grant entitled Vector competence of British mosquitoes to flaviviruses' awarded to Baylis, and a National Institute of Health Research Health Protection Research Unit in Emerging and Zoonotic Infections, vector theme, led by Baylis. The research was funded by the National Institute for Health Research Health Protection Research Unit (NIHR HPRU) in Emerging and Zoonotic Infections at the University of Liverpool in partnership with Public Health England (PHE) and Liverpool School of Tropical Medicine (LSTM). The views expressed are those of the author(s) and not necessarily those of the NHS, the NIHR, the Department of Health or Public Health England.

Availability of data and material

The data supporting the conclusions of this article are included within the article.

\section{Authors' contributions}

MSCB, DEI, PJM, JMM, GEL, TS and MB designed the study; MSCB, KS and GEC performed experiments; $M S C B$, TS and $M B$ analysed and interpreted data; MSCB and MB wrote the manuscript; all authors reviewed and approved the final manuscript.

\section{Competing interests}

The authors declare that they have no competing interests.

\section{Consent for publication}

Not applicable.

Ethics statement and consent to participate Not applicable. 


\section{Author details}

'Department of Epidemiology and Population Health, Institute of Infection and Global Health, University of Liverpool, Liverpool, UK. ${ }^{2}$ National Institute of Health Research Health Protection Research Unit in Emerging and Zoonotic Infections, University of Liverpool, Liverpool, UK. ${ }^{3}$ Centers for Disease Control and Prevention, Atlanta, USA. "Vector Biology Department, Liverpool School of Tropical Medicine, Liverpool, UK. ${ }^{5}$ Medical Entomology group, Emergency Response Department, Public Health England, Salisbury, UK.

Received: 5 April 2016 Accepted: 3 August 2016

\section{Published online: 15 August 2016}

\section{References}

1. Medlock J, Vaux A. Aedes (Aedes) geminus Peus (Diptera, Culicidae) - an addition to the British mosquito fauna. Dipterists Digest. 2009;16:147-50.

2. Medlock J, Snow K, Leach S. Potential transmission of West Nile virus in the British Isles: an ecological review of candidate mosquito bridge vectors. Med Vet Entomol. 2005;19:2-21

3. Medlock JM, Leach SA. Effect of climate change on vector-borne disease risk in the UK. Lancet Infect Dis. 2015;15:721-30.

4. Rees A, Snow K. The distribution of Aedes: subgenus Ochlerotatus in Britain UK: Dipterists Digest; 1996.

5. Medlock J, Vaux A. Colonization of UK coastal realignment sites by mosquitoes: implications for design, management, and public health. J Vector Ecol. 2013:38:53-62.

6. Marshall JF. The British Mosquitoes. Super roy 1938. 1938

7. Snow K. Mosquitoes. Naturalists' Handbooks Series. London: Richmond Publishers; 1990

8. Medlock JM, Vaux AG. Seasonal dynamics and habitat specificity of mosquitoes in an English wetland: implications for UK wetland management and restoration. J Vector Ecol. 2015;40:90-106.

9. Medlock J, Hansford K, Anderson M, Mayho R, Snow K. Mosquito nuisance and control in the UK - a questionnaire-based survey of local authorities. Eur Mosq Bull. 2012;30:15-29.

10. Petersen $L R$, Brault $A C$, Nasci RS. West Nile virus: review of the literature. Jama. 2013:310:308-15.

11. Ford-Jones EL, Fearon M, Leber C, Dwight P, Myszak M, Cole B, et al. Human surveillance for West Nile virus infection in Ontario in 2000. Can Med Assoc J. 2002;166:29-35.

12. Buckley A, Dawson A, Moss SR, Hinsley SA, Bellamy PE, Gould EA. Serological evidence of West Nile virus, Usutu virus and Sindbis virus infection of birds in the UK. The J Gen Virol. 2003;84:2807-17.

13. Buckley A, Dawson A, Gould EA. Detection of seroconversion to West Nile virus, Usutu virus and Sindbis virus in UK sentinel chickens. Virol J. 2006:3:71.

14. WHO: Global strategy for dengue prevention and control 2012-2020. 2012 [http://apps.who.int/iris/bitstream/10665/75303/1/9789241504034_eng.pdf] Accessed 13 May 2016

15. Bhatt S, Gething PW, Brady OJ, Messina JP, Farlow AW, Moyes CL, et al. The global distribution and burden of dengue. Nature. 2013:496:504-7.

16. Simmons CP, Farrar JJ, van Vinh CN, Wills B. Dengue. N Engl J Med. 2012; 366:1423-32.

17. Schuffenecker I, Iteman I, Michault A, Murri S, Frangeul L, Vaney M-C, et al. Genome microevolution of chikungunya viruses causing the Indian Ocean outbreak. PLoS Med. 2006;3:e263.

18. Rezza G. Dengue and chikungunya: long-distance spread and outbreaks in naïve areas. Pathog Glob Health. 2014;108:349-55.

19. Kuehn BM. Chikungunya virus transmission found in the United States: US health authorities brace for wider spread. Jama. 2014;312:776-7.

20. Mackenzie-Impoinvil L, Impoinvil D, Galbraith S, Dillon R, Ranson H, Johnson N, et al. Evaluation of a temperate climate mosquito, Ochlerotatus detritus (= Aedes detritus), as a potential vector of Japanese encephalitis virus. Med Vet Entomol. 2015:29:1-9.

21. Hadfield TL, Turell M, Dempsey MP, David J, Park EJ. Detection of West Nile virus in mosquitoes by RT-PCR. Mol Cell Probes. 2001:15:147-50.

22. Pongsiri P, Praianantathavorn K, Theamboonlers A, Payungporn S, Poovorawan Y. Multiplex real-time RT-PCR for detecting chikungunya virus and dengue virus. Asian Pacific J Trop Med. 2012;5:342-6.

23. Davis LE, DeBiasi R, Goade DE, Haaland KY, Harrington JA, Harnar JB, et al West Nile virus neuroinvasive disease. Ann Neurol. 2006;60:286-300.
24. Brown EB, Adkin A, Fooks AR, Stephenson B, Medlock JM, Snary EL. Assessing the risks of West Nile virus-infected mosquitoes from transatlantic aircraft: implications for disease emergence in the United Kingdom. Vector Borne Zoonot Dis. 2012:12:310-20. Larchmont, NY.

25. Platt KB, Linthicum KJ, Myint K, Innis BL, Lerdthusnee K, Vaughn DW. Impact of dengue virus infection on feeding behavior of Aedes aegypti. Am J Trop Med Hyg. 1997;57:119-25

26. Joshi V, Mourya D, Sharma R. Persistence of dengue-3 virus through transovarial transmission passage in successive generations of Aedes aegypti mosquitoes. Am J Trop Med Hyg. 2002;67:158-61.

27. Weaver S, Scott T, Lorenz L, Lerdthusnee K, Romoser W. Togavirusassociated pathologic changes in the midgut of a natural mosquito vector. J Virol. 1988:62:2083-90.

28. Weaver SC, Lorenz LH, Scott TW. Pathologic changes in the midgut of Culex tarsalis following infection with Western equine encephalomyelitis virus. Am J Trop Med Hyg. 1992;47:691-701.

29. Scott TW, Lorenz LH. Reduction of Culiseta melanura fitness by eastern equine encephalomyelitis virus. Am J Trop Med Hyg. 1998;59:341-6.

30. Mahmood F, Reisen WK, Chiles RE, Fang Y. Western equine encephalomyelitis virus infection affects the life table characteristics of Culex tarsalis (Diptera: Culicidae). J Med Entomol. 2004;41:982-6.

31. Hanley KA, Weaver SC. Arbovirus evolution. Origin and Evolution of Viruses. Oxford: Elsevier; 2008. p. 351-92.

\section{Submit your next manuscript to BioMed Central and we will help you at every step:}

- We accept pre-submission inquiries

- Our selector tool helps you to find the most relevant journal

- We provide round the clock customer support

- Convenient online submission

- Thorough peer review

- Inclusion in PubMed and all major indexing services

- Maximum visibility for your research

Submit your manuscript at www.biomedcentral.com/submit
Biomed Central 